\title{
Whose Wuxia and What Kind of Myth: A Wuxia Accompanying Text Perspective
}

\author{
Jinyan Sun \\ Associate Professor, School of Literature and Communication, \\ Yunnan Minzu University, Kunming, China \\ o8yano8@163.com \\ Dawei Han \\ Professor, School of International Education, \\ Hainan College of Economics and Business, Haikou, China \\ dawei.han@hceb.edu.cn
}

\begin{abstract}
Texts are the result of engravings in different social contexts, and they are culturally activated in different ways. The image of wuxia is formed by various accompanying texts sharing and participating in constructing a collection of wuxia narratives. By means of text-naming methods, authors, serialization of novels, film and television adaptations, criticism, and so forth, the image of wuxia operates in a continuous cycle that flows throughout texts that are gradually accumulated in the literary corpus. On this basis, it condenses and expresses a series of ideological discourses centred on topics such as gender and nation. These accompanying texts have diverse identities and play multiple roles in the cause of wuxia coming to be viewed as public heroes. They not only supply us with frameworks and positioning of wuxia novels but also provide cultural observations of society so as to participate in the construction of wuxia myths.
\end{abstract}

\section{Keywords}

wuxia - accompanying text - myth - gender identity - image construction 


\subsection{Paratext of Various Frame Factors of Wuxia ${ }^{1}$}

The concept of paratext was cumulatively constructed by Jean Genette in his discussion of 'cross-text relations'. His three serial publications, The Architext: An Introduction (1979), Palimpsests: Literature in the Second Degree (1982), and Paratexts: Thresholds of Interpretation (1987), contain in-depth discussions on paratext and its relations with readers. Genette believes that there has never been and will never exist a text without a paratext. A literary work is generally formed by the relations between main text and its paratext, the relation between main text and paratext is a kind of 'transtextual relation,' and the paratext is 'the notes or added elements that surround the text' (Genette, 1988: 63).

Researchers explain the paratext based on the relationship between the paratext and the main text. Genette believes:

A literary work consists, entirely or essentially, of a text, defined (very minimally) as a more or less long sequence of verbal statements that are more or less endowed with significance. But this text is rarely presented in an unadorned state, unreinforced and unaccompanied by a certain number of verbal or other productions, such as an author's name, a title, a preface, illustrations. And although we do not always know whether these productions are to be regarded as belonging to the text, in any case they surround it and extend it, precisely in order to present it, in the usual sense of this verb but also in the strongest sense: to make present, to ensure the text's presence in the world, its 'reception' and consumption in the form (nowadays at least) of a book. These accompanying productions, which vary in extent and appearance, constitute what I have called elsewhere the work's paratext, in keeping with the sometimes ambiguous meaning of this prefix in French (I mentioned adjectives like 'parafiscal' [a 'taxe-parafiscale' is a special levy] or 'paramilitary'). For us, accordingly, the paratext is what enables a text to become a book and to be offered as such to its readers and, more generally, to the public.

GENETTE, 1977: 1

1 Wuxia literally means 'martial heroes'; in this paper it refers to a genre of Chinese fiction and film concerning the adventures of sword-wielding chivalrous heroes.

2 Genette believes that there are five types of 'transtextual relations': intertextuality, relationship between positive and secondary texts, paratextuality, metatextuality, and hypertextuality. See Genette (2000: 71-73). 
The paratext can be further defined as: titles, subtitles, intertitles, prefaces, epilogues, dedications, opening information, illustrations, inserts, and other attached verbal and non-verbal signs. They provide a rich ecological environment and atmosphere for the text: 'sometimes even an official or semi-official comment is provided. The simplest readers, who are least interested in peripheral knowledge, can hardly be as imagined or declared, always possess the above-mentioned materials easily' (Genette, 2000:1).

Marie Maclean applies speech act theory to distinguish the text into first order and second order: the paratext involves a series of first-order illocutionary acts in which the author, the editor, or the prefacer frequently use direct performatives. They inform, persuade, advise, or indeed exhort and command the reader. The world of fictional text is the second-order speech act (Maclean, 1991: 274). In order to further discuss intertextuality, Zhao Yiheng suggests that texts other than the main text should be classified into several types of 'paratext'. He believes that

In terms of signification, the various cultural factors carried by a text can be generally divided into two categories: the first category is the 'production accompanying a text' ${ }^{3}$ that has been added before the text is produced. It includes the pre-text and the 'explicit accompanying text' generated at the same time as the text, namely the paratext and the type text; the second category comprises explanatory accompanying texts (metatext and chain text) [which] come into being when the text is received. Thus pre- or post-texts are 'productive' or 'interpretative'.

ZHAO, 2O11: $153^{4}$

As for the references and notes, which are classified as paratext by Genette, Zhao Yiheng classifies them as the subcategory of chained texts under the category of 'interpretive accompanying text', which can be added to the discussion of pre-/post-texts, as shown in the relations between The Golden Lotus and Water Margin, thereby expanding the rationale for intertextuality.

3 The concept of 'accompanying text' refers to a large number of additional factors carried by the text that actively participate in the formation of the meaning of the text and seriously affect the interpretation of the meaning. This includes, for example, subtexts (e.g. authors and publishers), architexts (e.g. texts published by the same publishing house or in the same genre), pre-texts (e.g. quotations and allusions), metatexts (e.g. reviews), chain texts (e.g. reference texts and network links), and successive texts (e.g. television and movie adaptations), all of which Zhao categorizes within the framework of 'generative'/'productive' accompanying texts and 'interpretative' accompanying texts. See Zhao (2011: 141-158).

4 Unless otherwise stated, translations are by the authors. 
In this way, the paratext, the 'framing elements' of the text, is surrounded by titles, inscriptions, the author's name, prefaces, illustrations, publishers, and the bindings of the books. The main issue for the paratext is not to look nice' as a frame around the text but rather to ensure that the intent of a text is consistent with the author's goal (Genette, 1977:407). In other words, the function of the paratext (framing elements) is to entice ideal readers to follow the reminders of the framing elements to maximize the text's intent. For example, although the publication of Jin Yong's wuxia novel The Deer and the Cauldron was unacceptable to Jin Yong's wuxia fans, it is still not included in the inventory of historical novels as what he commented in the postscript: 'It's not like a wuxia novel anymore; rather it's a historical novel' (Jin, 1994b: 1963). The novel was serialized in a supplement of the Ming Pao newspaper, a publication known for publishing leisure' novels, and was included in the inventory of his fourteen symbolic publications. ${ }^{5}$ Therefore, although it is generally defined as a rebellion against wuxia novels, it is still considered as belonging to the genre of wuxia novels because various framing elements determine its status as a 'non-historical novel'.

The paratext, the framing element of the wuxia genre, also participates in the construction of the hidden gender myth in wuxia novels. In particular, the title, pen name, cover design, and illustrations all highlight or presuppose the 'male' myth of wuxia. The most notable framing element is the nomenclature of wuxia novels, represented by two frequently used characters, 'wu' and 'xia', with the aim of profiling their combined effect of its 'toughness' and 'virility'. Similar cases can be found from Tales of the Extraordinary Xiake of Jianghu and The Legend of Chivalrous Heroes of Modern Times by Pingjiang Buxiaosheng and from Jin Yong's fifteen books. ${ }^{6}$

\subsection{Masculine Style in the Paratexts of Wuxia Novels}

In practice, myth can be realized as a series of symbols combined through narration. It embodies an all-encompassing concept of reality of a certain

5 It was discovered that the first characters of the first fourteen wuxia novels' titles by Jin Yong can be joined together to form a couplet with seven characters on each line. The fourteen books are: The Young Flying Fox, Fox Volant of the Snowy Mountain, A Deadly Secret, Demigods and Semi-Devils, The Legend of the Condor Heroes, White Horse Neighs in the Western Wind, The Deer and the Cauldron, The Smiling, Proud Wanderer, The Book and the Sword, The Return of the Condor Heroes, Ode to Gallantry, The Heaven Sword and the Dragon Sabre, Sword Stained with Royal Blood and Blade-Dance of the Two Lovers.

6 Jin Yong wrote 15 novels in total. Apart from the above mentioned 14 novels, Sword of the Yue Maiden was initially attached to the Ode to Gallantry and later collected in the Collections of Jin Yong's works. 
designated group; that is, a world view. Wuxia novels are constructed as masculine myths through various means that are related to the cognition of strong males and weak females. The myth is well established. To recall Charles Darwin in The Descent of Man (1871):

It is generally admitted that with woman the powers of intuition, of rapid perception, and perhaps of imitation, are more strongly marked than in man; but some, at least, of these faculties are characteristic of the lower races, and therefore of a past and lower state of civilization. The chief distinction in the intellectual powers of the two sexes is shown by man attaining to a higher eminence, in whatever he takes up, than woman can attain - whether requiring deep thought, reason, or imagination, or merely the use of the senses and hands.

Quoted in GOULD, 1993: 267-268

Zhang Dachun, a well-acclaimed wuxia novelist and expert in stylistic study from Taiwan, commented when discussing the structure of wuxia novels: 'In the early days, I am afraid the reason why only He Yufeng (aka Sister Thirteen), the leading female character in the Legend of Heroic Sons and Daughters, had a martial arts master named Deng Jiugong is because it is difficult for ordinary readers to accept a woman possessing superior martial art skills to men; the role of male master in the book was to dispel doubts' (2004: 276). As is reflected in his judgment on the structure of wuxia novels, choosing a male as the main character was in line with convention in the early genre of wuxia novels. Lin Baochun, a prominent researcher of wuxia novels, notes that among wuxia fiction writers in Taiwan:

Male writers have a natural advantage over female ones in wuxia. This is due to the masculine nature of wuxia works. Wuxia novels are not only popular among male readers, but also the writers are mainly males. As far as I know, female wuxia writers, though there are a few (about one per cent), such as Fang Ezhen, Diyi, and others, they are all non-professional wuxia writers.

LIN, 2011

Similarly, Han Yunbo, a wuxia novel researcher who put forward the concept of 'twenty-first-century Chinese mainland New Wuxia', summarizes the characteristics of wuxia writing in the new century thus: 'women changed from passive to active roles, from desired objects to subjects of narrative, and women truly became the main characters in wuxia novels for the first time' 
(Han, 2004:150-156). It also demonstrates, conversely, that the protagonists of wuxia novels in Chinese mainland were males before the twenty-first century.

To a large extent, the 'male' gender orientation of wuxia is established through several forms. The following sections focus on the two paratexts of wuxia novels, the author's pen names and illustrated symbols, to discuss how wuxia novels shape gender myths.

\subsubsection{The 'Masculine' Tendency in Pen Names}

Michel Foucault pointed out: 'The name of the author is thus a variable, a signifier, which accompanies only certain texts to the exclusion of others' (Foucault, 1977: 124). In other words, the author's name is often used for multiple purposes and as a valued symbol. Before the late Qing dynasty (1840-1912), poetry was considered 'high class' and the novel 'low class'. The literati would thus often use pen names to hide their identities when writing novels. With the development of the printing industry in the late Qing dynasty, the two camps of popular fiction, wuxia and romance, were still considered low class and categorized in low culture. Compared with the May Fourth novelists, who occasionally used their real names, ${ }^{7}$ most writers of wuxia novels generally used pen names, such as famous romance writers of the republican period like Qin Shouou, Wang Xiaoyi, Zhang Henshui, and Liu Yunruo. The themes of wuxia novels show that Xiake come and go outside the world of Jianghu and practise chivalry and justice; they are similar to the man who aspires to sacrifice himself to manage public affairs for the common good, and this is the reason wuxia novelists chose masculine pen names in the republican period.

How was masculinity made manifest in the use of pen names? First, the pursuit of 'Tao'. In 1916 Xiang Kairan chose the pen name Pingjiang Buxiaosheng for his Unofficial Stories of Overseas Chinese Students in Japan and retained it thereafter. The original idea was to invoke the concept of buxiao (inferiority) from Tao De Jing - 'the entire world says that, while my Tao is great, it yet appears to be inferior [to other systems of teaching]. Now it is just its greatness that makes it seem to be inferior. If it were like any other [system], for long would its smallness have been known!. (Wang Bi, Wei Yuan, 1992: 41) Unlike any concrete things, once the concept 'my Tao is great' is realized in practical means, it will not sustain as time passes by. In this context, 'Buxiaosheng' signifies both pride and humility, which implies a man with ambition or unfulfilled aspirations. Similarly, Gu Jingcheng used the feminine pen name Meiqian

7 For example, in the novel Three Years written by Hu Shanyuan from Musa Club, the main hero and heroine are Hu Shanyuan and his wife Xu Yun, telling the three-year life of the two from acquaintance, love, and marriage to death. 
Nüshi ('Pretty and Graceful Lady') to make his early fame as a social romance writer of Naihe Tian and Pengmen Honglei. He was even pursued by a lovecrazed follower pen-named Zui Hong Sheng ('Fascinated Young Man') who asked for 'her' photo in a letter. He later changed his pen name to Gu Mingdao for the publication of his seminal novel The Lady of Steel, as well as for Firm but Gentle Thrill of Kung Fu. The name Mingdao recalls a quote from the Chinese classic The Literary Mind and the Carving of Dragons: On Tao, the Source by Liu Xie: 'Tao is handed down in writing through sages, and sages make Tao manifest in their writings.' (Liu, 2004: 7) It thus expresses his ambition to realize Tao through seemingly insignificant wuxia novel writings.

The second way in which masculinity was manifested in pen names is the symbolism of personality traits like elegance and heroism. Examples include (pen name is followed by the approximate meaning in English and the author's real name): XiaoYi ('Elegant and Graceful', Xiao Jingren); Xiao Se ('Desolate Sound of Wind', Wu Ming); Gu Long ('Ancient Dragon', Xiong Yaohua); Long Chengfeng ('Wind-Riding Dragon', Chen Jianguang); Gu Rufeng ('Ancient Wind', Xiao An; Xiao Yi's younger brother); Wolong Sheng ('Student of Wolong8 Academy', NiuHeting); Long Xiang Zi ('Magnificent and Mighty Man', Chen Longxiang); Shangguan Ding (this is the pen name of three brothers of the Liu family and means 'Three Legs of a Cauldron', symbolizing the three brothers working together to reach the top); WulingQiaozi ('Woodman from Wuling', XiongRenqi); Yunzhong Yue ('High Mountain in the Clouds', Jiang Lin); and ZhugeQingyun ('Man of Stature', Zhang Jianxin).

The third manifestation was to demonstrate the virility of 'wu' or to use pen names named after weapons: for example, Sima Ling (ling means 'arrow', Wu Siming) and Wu Ji ( $j i$ means 'halberd' or 'polearm', Wang Ying). The fourth was to create a desolate sense of the 'lonely traveller', such as in the case of Duguhong ('Loner Red', Li Bingkun); Canglangke ('Wave-Surging Man', Yao Kao); Dongfang Hun/Jiangshang Hun ('Oriental Soul' / 'Soul on the River', Yang Rundong); Can Mo ('Residue Ink', Zhao Bohua); Haishang Jizhu Sheng ('A Man Striking a Zhu ${ }^{9}$ on the Sea', Cheng Tiewu); Nanxiang Ye Sou ('Wild Old Man in Southern Hunan', Gu Yexin); Ye Leng ('Cold Leaf', Guo Yunxiu), Xi Zhaohong ('Red Setting Sun', Xin Yanwu), and Liu Canyang ('Willow in the Setting Sun', Gao Jianji), and so on.

Another feature worth addressing is that some female wuxia writers would occasionally and consciously choose to use neutral or even masculine pen names. For example, Xie Xiulian, as well as using the better-known pen name

8 Wolong means 'crouching dragon'.

9 A zhu is a traditional Chinese percussion instrument. 
Di Yi, also used Lingkong Zi and Ling and Kong, punning on extraordinary gravity-defying moves and a gentle and lofty personality. The character 'Zi' in traditional Chinese denotes a respected title given to an exquisite and unpredictable master - for example, Kong Zi (Confucius), Meng Zi (Mencius), and Hanfei Zi (Master Hanfei). Later the semantic content of 'Zi' was expanded to refer to an adult male, as in Shi Zi ('Scholar'), Cai Zi ('Talented Man'), Zhou Zi ('Boat Man'), and Chu Zi ('Chef'). Compared to her real name (Xie Xiulian) and pen name (Di Yi), 'Linkong Zi' is more likely to evoke both the imagination of wuxia and gendered associations. Putting aside an old pen name and creating a new one to best fit the identity of a wuxia writer, as far as the author is concerned, is not an insignificant decision. The decision of female writers to adopt male pen names has, intentionally or unintentionally, participated in the construction of the male myth in wuxia novels.

\section{2 .2 \\ Mismatched and Male-Dominated Illustrations: The Illustrations of Jin Yong's Wuxia Novels}

Illustrations are used in literary books either to decorate the layout or to depict the content of the text, thus forming the phenomenon that 'image and text' are mutually foregrounded. But as the British iconologist Peter Burke points out: 'it would be unwise to attribute to these artist reporters an "innocent eye" in the sense of a gaze which is totally objective, free from expectations or prejudices of any kind. Both literally and metaphorically, these sketches and paintings record a "point of view"' (Burke, 2008: 16). When it comes to female xia, the illustrations and texts in wuxia novels seem to unconsciously present an inconsistent 'image-text' state.

Analysing examples of illustrations from the 1994 Joint Publishing edition of Jin Yong's novels ${ }^{10}$ can lead us to a better understanding of the issue. Jin Yong's wuxia novels are widely acclaimed to be exemplary; he commanded a wide and demographically broad readership and was recognized both as a forerunner of modern wuxia literature and as a master of Chinese studies ${ }^{11}$

10 Most of Jin Yong's works were initially published in instalments in Hong Kong newspapers between 1955 and 1972, spanning the more turbulent years in Chinese history. Between 1970 and 1980 Jin Yong revised his wuxia novels, and the new works were published serially in China from 1980 and as a collection in Taiwan in 1979. The complete thirty-six-volume collection in Simplified Chinese was published in Beijing by sDx Joint Publishing in 1994. In 2001 the Joint Publishing edition contract expired and was transferred to Guangzhou Publishing House. From 1999 to 2006 Jin Yong revised his works for the second and last time. The newer revised edition was published in 2007. Citations in this article refer to the 1994 edition.

11 For further information, see Wang Yichuan (1994). Jin Yong ranked fourth, after Lu Xun, Shen Congwen, and Ba Jin, and ahead of Lao She, Yu Dafu, Wang Meng, Zhang Ailing, and Jia Ping'wa. 
in the twentieth century. Moreover, Joint Publishing enjoyed a reputation for high quality and taste. We thus might expect that the mode of presentation of the Joint Publishing edition to reveal certain hidden views and explore the imagination of characters narrated in his wuxia novels.

Most of the illustrations in Jin Yong's wuxia novels are dedicated to depicting male swords men; even if there are swords women, they are rarely the main figures of the illustrations. In the overall layout of an illustration, the main position of the female character tends to be obscured, marginalized, or replaced by the foregrounded image of the male character(s), or minimized in terms of spatial ratio. The following text passages with illustrations serve as representative examples. The first example is from chapter 30 (titled 'East and West Will Always Be Divided like Enemies') of The Heaven Sword and Dragon Sabre.

\section{The Female Swordswoman in Sideways Profile}

Taj-kis smiled and said, 'Father, your daughter grew up by the sea; since I was little my water skill has been very good.' Immediately she unsheathed her sword and leaped into the middle of the river. Standing on the ice she turned her sword to make a circle about two feet in diameter. With her left foot she treaded on the ice; 'crack!' the round ice broke and she jumped into the water.

JIN, 1994: $115^{8}$

At that moment a gust of sea breeze from the north brushed their clothing. Xie Xun continued his narration, 'Each time I recalled the scene by the "bi shui han tan" that day, it always seems like yesterday to me. Taj-kis was wearing a lavender gown. Standing on the ice that day, she looked like the "ling bo xian zi" [Immortal/Deity/Goddess Ling Bo]. Silently and instantly she disappeared into the water below; the crowd of warriors was amazed. Looking at Taj-kis in the water, Han Qianye immediately withdrew the arrogant expression on her face and, holding a dagger in her hand, jumped into the pool.

As we can see in Figure 1, the only woman (Taj-kis) is placed at the front on the right of the illustration, with long eyelashes and a cloud bun towering tall. She is in a slim ruffled gown and a pair of non-legging style trousers indicating her gender. In line with the text description, we find two inconspicuous shifts of position: the first is the change of standing position of the narrator. In The Heaven Sword and Dragon Sabre, Xie Xun is the narrator in the passage, and all the actions of Taj-kis, Han Qianye, and others are viewed from his perspective. According to the text, Xie Xun is supposed to be on the bank by the river, but 


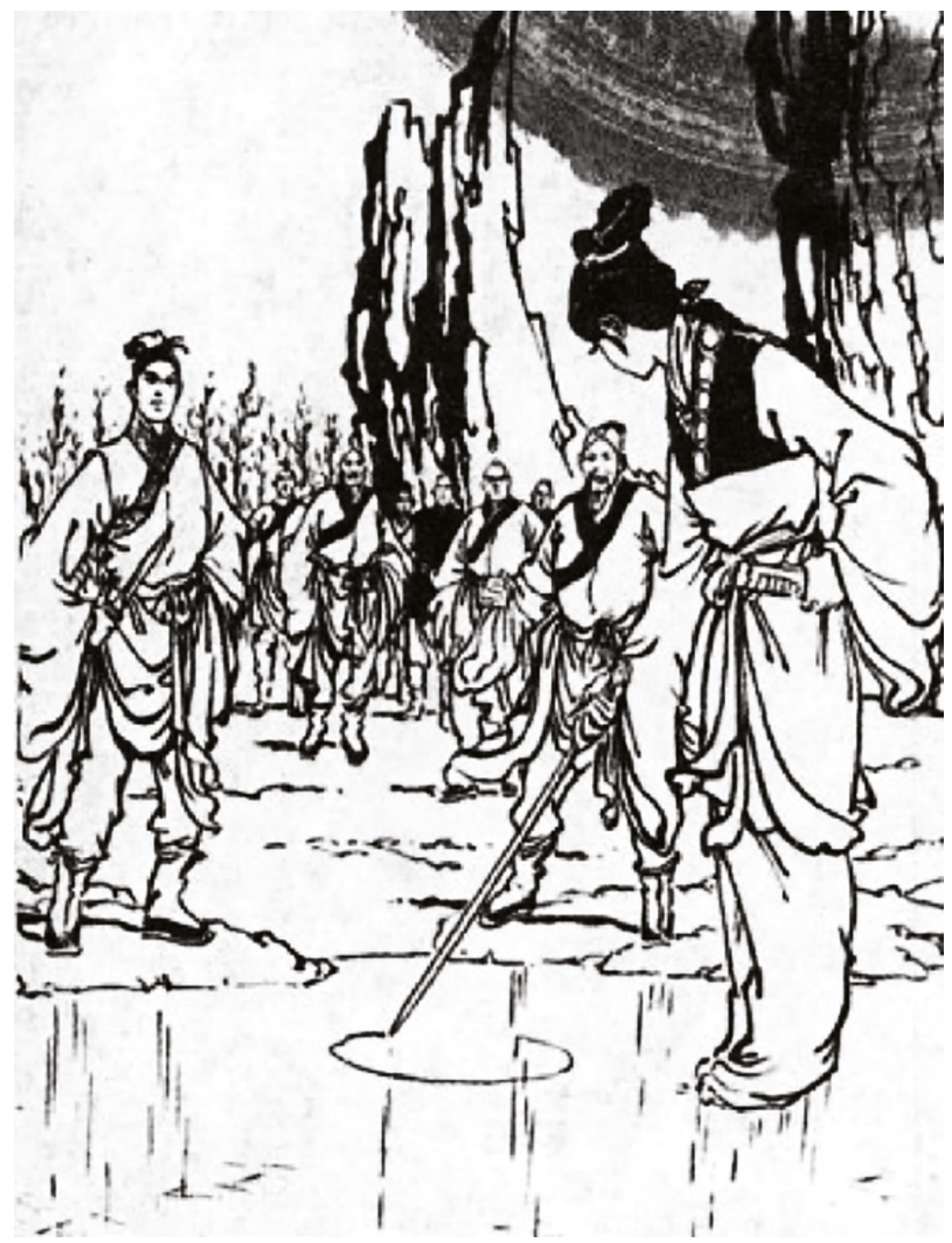

FIGURE 1 Illustration from chap. 3 o of The Heaven Sword and Dragon Sabre JIN, 1994:1149 
in the illustration he is actually standing in the pond; in addition, in respect of the ratio of characters used in the narration, Taj-kis is the centre of focus, while Han Qianye only appears intermittently between Hu Qingniu's and XieXun's narrations. Regarding the locations of the river and the other swordsmen, it is reasonable to have Han Qianye depicted on the side or even in the background of the image. Despite the narrative focus, Taj-kis is only depicted a sideways shot in the illustration, looking towards the men. The men, who are supposed to be backgrounded according to the text, appear here front-facing, especially the man holding the dagger, and are portrayed as handsome and athletic rather than plain-looking and fat. It is evidence that the illustrator rather furtively chose to divert the perspective of the narration for the sake of a positive depiction of the male swordsmen.

The second example is from chapter $3^{2}$ (titled 'Rushing River and Rigged Shore') of The Legend of the Condor Heroes. (Joint Publishing, 1994)

As the boat was ashore, the boatman dropped out the anchor. Guo Jing saw there were more than twenty boats that also dropped their anchors on the nearby bank. Huang Rong asked a man standing nearby, 'Brother, what is this place?' 'Green Dragon Village,' that man replied. Huang Rong nodded. She only kept close attention on the mute boatman. She saw him make some hand signals with a big man standing on the sloping bank. Suddenly the boatman took out an axe and with two chops he cut the mooring rope. Immediately afterwards he raised the anchor. As the boat became free, the rushing water washed it out down the river. It made a sudden turn until the hull slanted sideways and flushed away as if it were flying down the river. The people on the shore cried out in alarm.

After the Green Dragon shore the riverbed changed abruptly, creating a short waterfall. The river current was so strong that water was splashing everywhere. The mute boatman kept his hands on the rudder, with eyes steadily fixed on the surface of the river. His two helpers held long punting poles in their hands, standing on the either side of him. It seemed like they were guarding against the boat having an accident, but it also looked like they were protecting the boatman from being attacked by Jing and Rong.

JIN, 1994: 1176 


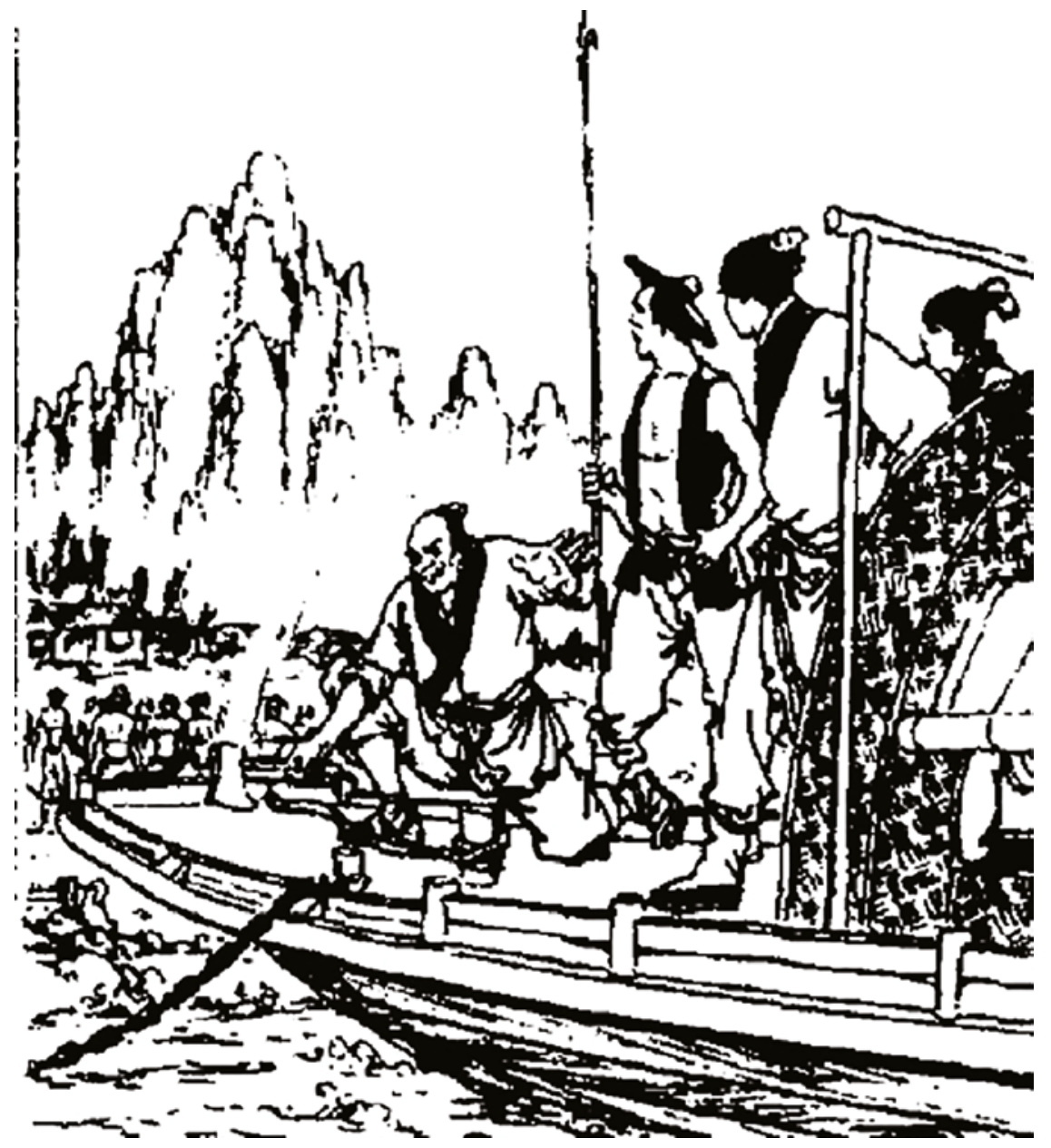

FIGURE 2 Illustration from chap. 32 of The Legend of the Condor Heroes

JIN, 1994: 1161

In Figure 2, there are 'people on the shore' gathered in the market in the background, looking out to the boat with three men and one woman on board. The space provided for the woman is extremely limited, only showing her above the shoulders to the right of the image. Contrast that with the text: 'Huang Rong nodded. She only kept close attention on the mute boatman. She saw him make some hand signals with a big man standing on the sloping bank.' The Chinese characters 'zhi kanjian' (only see) here expresses the perspective of Huang Rong; in addition, Huang Rong is also the heroine of the story. Yet in the illustration she is standing behind the three men, in the background, 
with blurred facial features and only her upper bust visible; the men are foregrounded and the space left for her is extremely cramped.

Even if women are the main characters in the wuxia narrative, it seems from looking at these illustrations that the painter chose to obscure their dominant positions in various ways. According to Charles Sanders Peirce's semiotics, every symbol has two objects: dynamic object and immediate object. The former is the 'really effective but not immediately presented object', the latter is the 'object represented by that sign' (Cornelius, 2003: 19). Correspondingly, symbols have three interpretants: the dynamic interpretant, immediate interpretant, and final interpretant. The immediate interpretant of the illustration comes from the text of the novel and its illustration; the dynamic interpretant comes from the image signs themselves, which are surrounded by cultural context and carry the 'view' of the painter. The final interpretant of the illustration is the reinterpretation in the cultural context after the integration of the former two interpretants. It is on this third basis that the illustrations in jin Yong's wuxia novels, presumably in other wuxia novels, to certain extent, show a gender-related imagination.

\subsection{The Symbolic Effect of the 'Male' Heroin Wuxia Novels}

An author of a literary work often chooses personal 'signatures' (e.g. their pen name, character pseudonyms, other names, etc.) consisting of a specific word that conceals specific sentiments or displays certain tendencies. ${ }^{12}$ Wuxia novelists are no different. The author's pen name and the structure of the illustrations help to coordinate and condense a series of overlapping ideological issues. These issues revolve around the construction of gender identity, including women's intentional or unintentional participation.

The signature methods of wuxia novelists and the structure of posters and illustrations in wuxia works are individualized behaviours of the creators themselves, but they are also subject to the constraints of sociopolitical, economic, and cultural contexts, and may demonstrate certain tendencies in a specific historical period. For example, one researcher has concluded that the characteristic trait of 'New Wuxia' writing in mainland China in the twenty-first century is 'the development of the female subjective consciousness, allowing [female authors] to surpass the male-centrism that has potentially clamped

12 For example, Zhou Zuoren pointed out in Characters in Lu Xun's Novels (1981: 74) that 'some pen names and the names of people and places in the novels were given by the author at the time with intended meanings. Even if it is meaningless, is actually one of the intentions'. 
down on the new wuxia such as Jin Yong's wuxia' (Wang, 2007: 35-39), thus countering the correlation between previous wuxia novels and 'maleness'. From the three different 'meaning' steps of the symbolic representation process (the sender's intended meaning, the textual meaning of signs, and the interpretive meaning from receivers), the text does not enjoy an independent ontological existence; more often than not, it is not the product of the writer's wishful thinking but the result of the 'conspiracy' between the writer's imagination and readers' demand. Therefore, from the perspectives of the sender and receiver of signs, the masculine pen names and the visual images of illustrations profiling and foregrounding male subjects impose specific meanings.

First of all, in terms of the intent of the senders of signs, the fictional world of Jianghu tends to be the departure and resting place of a strong will - in this context, the male gender is likely to fit with the reference to 'strength'. The use of male pen names is viewed as a positive sign to approach this reference: 'you may just take a glance at the pen names and immediately figure out their professions, such as Wolong Sheng and Pingjiang Buxiaosheng, who're obviously involved with wuxia writing' (Zhang, 2001). In the same vein, the positioning of males in illustrations also participates in the construction of a 'masculine' hero by adjusting the function and value of an individual sign.

Even female wuxia writers tend to participate in gender construction, intentionally or unintentionally. In addition to the pen names of the aforementioned female wuxia novelists, such intention can be identified in their writings. For example, Bu Feiyan wrote in a review of Li Ying's The Four Female Constables that 'in this picture, same as their male counterparts, women are drinking and wielding swords, are well dressed, riding white horses, punishing the violent and evil and demonstrating consummate skill in martial arts' (Bu, 2005: 41). In her description, women need to compete with men for the resources being allocated in advance. The prerequisite for the competition is that women must conform to the actions and behaviours of swordsmen so as to be recognized as part of the swordsmen community.

Secondly, from the perspective of sign receivers, the creation of wuxia signs is market-oriented. The author's pen name, 'whether it is a woman disguised as a man or a man disguised as a woman, there is only one purpose; that is, the gender fictitiousness of the author's pen name is conducive to the acceptance and dissemination of specific works' (Yuan, 2009: 41). Since the 1980s, with the transformation of the wuxia consumer market, the situation has undergone noticeable changes. With the gradual normalization of online writing and reading, female authors and audiences have actively engaged in wuxia themes, making women the regular protagonists in wuxia novels, and variants such as fantasy novels, one case in point being the recently released TV series 
adaptation of the wuxia novel Novoland: Pearl Eclipse by Xiao Ruse. However, in the early development of wuxia novels, the proportion of the audience of wuxia is predominantly male, and such characteristic is identified in the following discussion of the genre of text.

When discussing various types of signification activities of culture, Zhao Yiheng points out:

Subcultural texts are often generated for social classes with insufficient exposure to culture and regular education; these people tend to choose products with easier forms of signification and interpretation; anticultural texts are often produced for people with comparatively higher educational backgrounds, and the projected readers are almost professional (specifically trained) or semi-professional. With regard to the audiences of the two types of texts, their social status composition is not as stable as the composition of readership.

ZHAO, 1994: 200

Wuxia novels are at the bottom of the genre level classified by Confucian cultural philosophy, and are dependent on mainstream culture in terms of value orientation; however, consistent with the conclusions discussed by Zhao Yiheng on cultural research, since the wuxia novel is categorized as a subcultural genre and thus at the bottom of meaning and power distance, its production is mainly targeted at people with lower levels of education and cultural capital.

In the republican period Chinese essayist Mao Dun strongly opposed wuxia novels, noting that 'the majority of wuxia novel readers are ordinary urban residents, the so-called petty bourgeoisie, [whereas most] wuxia film viewers ... are ill-educated urban young dwellers' (Mao, 1933: 3). In the 199os Chen Pingyuan noted: 'as a popular art, wuxia literature is mainly [there] to satisfy the need for diversion and entertainment among [the] city-dwelling masses, ... as for those who lack the basic knowledge to appreciate fine arts, wuxia novels match their expectations' (Chen, 2010: 57-58). In China people from the middle and lower classes are under tremendous pressure in their daily lives, and perhaps 'wielding swords on horses' across the world fits their imaginary roles of 'making meritorious deeds'. On one hand, wuxia symbols serve to fulfill the expectations of so-called 'ordinary men' to rectify their minds and regulate their families, their country and the wider world in a virtual world; on the other hand, they cater to the needs of a certain group of readers by addressing their unfulfilled desires. Simply put, such demand starts with the gender selection of wuxia symbols. 


\section{Publishing Mechanisms, Reading Ethics, and Wuxia 'Distribution' Myth}

All symbolic text is a combination of main text and accompanying text. Wuxia novels and films have always possessed a very high market appeal, ${ }^{13}$ and their 'accompanying texts' have made substantial contributions.

Zhao Yiheng believes that accompanying texts are signs of the 'contract' between the text and culture: they appear outside the main text, such as the title of a book or film, or inside the main text, such as genre. As mentioned earlier in section 1.1, he classifies the two categories of (1) productive/generative accompanying text and (2) interpretative accompanying text. Productive/ generative accompanying text includes pre-texts (quotations, allusions) and explicit accompanying texts such as paratexts (the book title, the author name or pen name, the publisher) and type texts (texts belonging to the same genre, texts published by the same publisher). It also includes immediate texts (the many influencing factors involved in the writing of a text $\left.\mathrm{t}^{14}\right)$. Interpretative accompanying text includes metatexts (reviews, reception of the text in media, academia, and wider arts and culture industry), chain texts (reference works, links with networked texts ${ }^{15}$ ), successive texts (film and drama adaptations, spoofs, parodies), and other explanatory accompanying text (Zhao, 2011: 141-150).

We diverge slightly from Zhao by breaking up his first category and considering, in the context of wuxia literature, (1) generative accompanying texts (which exist before the text is created), (2) explicit accompanying texts (which are generated at the same time as the text), and (3) interpretative accompanying

13 Zheng Yimei (1984: 135) describes the wuxia reading market in republican China thus: 'In recent years, novels have sprung up like bamboo shoots after a rain and have been published one after another. Most readers like to read wuxia novels, according to a friend who is familiar with the situation in ... the Eastern Library [which] ... purchased copies of Tales of the Extraordinary Xiake of Jianghu. So many people borrowed it, and soon the pages of the book were worn out and the characters were illegible, and they could no longer be read. The library bought one more copy, but it soon became illegible. So until the January 28 thbattle, this book has been purchased fourteen times. The appeal of wuxia novels is amazing.'

14 Zhao gives the example of Rilke's The Duino Elegies symbolizes the pinnacle of the German poet Rainer Maria Rilke. It which deals with major themes such as survival and death, humanity and divinity, and represents the depth of human understanding of the world.

15 Zhao gives as an example the links between the films Mei Lanfang and Mozart. Mei Lanfang, directed by Chen Kaige, tells the life story of the Chinese master of Peking Opera, Mei Lanfang. Mozart, a film directed by Milos Forman, presents the life of the genius from the perspective of a court musician called Salieri. 
texts (which come into being after the text is received). All three are closely related to the record high publications of the wuxia genre.

First, in terms of generative accompanying texts, Chinese chivalrous culture is the pre-text of wuxia novels and films. The culture of hero-worship of swords man is receptive to various forms of wuxia narrative.

Second, in terms of explicit accompanying texts, readers and viewers of wuxia novels and films are often influenced by the existing characters, publishers, actors, directors, and so on (type texts). Wuxia novels from Taiwan are published by specialized publishing houses or magazines (subtexts). Among the former, the 'Eight Books' of Zhen Shan Mei, Spring and Autumn, Damei, Siwei, Haiguang, Mingxiang-Xinxing, Tsinghua-Xintai and Nanqi Store are the most famous. Zhen Shan Mei Publishing House is not only the earliest professional wuxia publishing house in Taiwan, with its printing, binding, and production quality being widely recognized, but it is also publishes the most prestigious wuxia novelists in Taiwan, including Sima Ling, Gu Long, and Shangguan Ding. In addition, there are specialized wuxia magazines such as Wuxia World, The Spring and Autumn of Wuxia, History and Wuxia, and so forth, that started publishing in Hong Kong. From the perspective of the audience of wuxia novels, the quality of wuxia works published by these publishers and magazines is guaranteed.

In film and television works, the most famous wuxia stars are Bruce Lee, Jackie Chan, Jet Li, and Donnie Yen; the film directors are Zhang Che, Chu Yuan, John Woo Yu-Sen, Ang Lee, Zhang Jizhong; and wuxia instructors are Yuan Heping, Yuan kui, and Cheng Xiaodong, among others. These individuals are capable of connecting with their roles and have brought to life many fictional events on screen, which has greatly affected the box office revenues of wuxia films.

Thirdly, in terms of interpretive accompanying texts, adaptations of and between novels and films and comics (chain texts, successive texts) can create a reading boom of wuxia works. The following segments are in-depth analyses of the influence that the accompanying texts of wuxia novels and films have had on the publication and distribution of wuxia novels and films.

\section{'Accept Nothing but Wuxia, Publish Nothing but Wuxia':}

The Proud Life of the Wuxia Genre

The writers of Chinese popular literature in the 1920 s were writing and discovering popular novels at the same time. When writing popular novels, the writer realized that the text will be read by many audiences. Due to this presupposition, writers were obliged to track down and confirm the types of novels that were mostly accepted by the majority of audiences. This ushered in a bold 
attempt at the advent of wuxia novels. The following quotation is taken from a review by popular writer and literary editor Bao Tianxiao in Memories of Chuanyinglou:

After the publication of Unofficial Stories of Overseas Chinese Students in Japan, the sales were very satisfactory, so a friend of mine in Japan told me that Pingjiang Buxiaosheng (Xiang Kairan) is a man of talent.... I asked him to write for Week magazine, and he agreed to write 'The Supplementary Stories of Oversea Chinese Students in Japan' and 'Hunter's Journal'.... Later, he was spotted by Shen Zifang, the owner of the World Publishing, and Shen asked me: 'Where did you hunt this treasure?' So he tried all means to ask Xiang Kairan to write novels for World Publishing, and promised him a very competitive remuneration. He was asked not to write books like Unofficial Stories of Overseas Chinese Students in Japan but write first-class legendary novels, such as the books of swordsman, warriors, and spirits, I admit it is a sharp eye of doing business. At that time, people were tired of reading the so-called romance novels in Shanghai, and it was bound to change their tastes.... With Mr Xiang's versatility, he created a series of Tales of the Extraordinary Xiake of Jianghu, one after the other, and thus blazed the trail of Shanghai wuxia novels.

BAO, 2009: 139

This passage not only reveals the reason why Xiang Kairan switched from writing social novels to writing wuxia novels. It also implies the lure of material gains that later writers of wuxia novels were enthusiastic about; the publisher's 'business insight' has always been their main focus.

Such a way of teasing out the outset of the twentieth-century wuxia novel seems to be somewhat embarrassing. However, in the huge network of the publishing industry in Shanghai and Tianjin from the 1920s to the 1940s, the drastic ups and downs of wuxia novels are closely related to the entire reading market, and it is difficult to ignore it after all. In the 193os, wuxia novels came under attack for being' all subject to the "triangulated" cycle of "business acumen" between novelist, readers, and publishers' (Shuo huaren, 1933: 21). During this period, according to Zheng Yimei, publishers really were following the idea of 'accept nothing but wuxia, publish nothing but wuxia' (Zheng, 1984: 135). Most professional writers needed to rely on novel writing to make a living and relied heavily on publishers for their knowledge of readers' tastes. Even famous writers of romance such as Li Dingyi, who skilfully wrote Mourning 
Girls and Shadows of Tears on the Red Window, also strode across Jianghu and wrote Monk Tales and Heroes of This Mortal World. Gu Jingcheng/ Mingdao (using Meiqian Nüshi as his pen name) started to write a novel of romance 'since Xiang Kairan'sTales of the Extraordinary Xiake of Jianghu caused a sensation, spurring newspaper editors and publishers to become enthusiastic about wuxia. Gu Mingdao also changed his course as soon as the popular mood changed. From 1923 to 1924 , he started to write wuxia and published a wuxia novel (Zhang Gansheng, 1991: 147) in Detective World magazine." Zhang Henshui even had to add characters to his Fate in Tears and Laughter: 'The publishers, according to their usual style, are afraid that there is no xia in the book, which may decrease the reader's appeal, so I was repeatedly asked to add two swordsmen.' (Zhang, 1981: 192-193). With such kind of allure, marketability of the genre of wuxia novels developed enormously.

Were we to situate ourselves between 1920 and 1940, we would have no right to make bold predictions about the future development of Chinese novels and even literature due to the popularity of wuxia novels of a 'vulgar and inferior' quality. Retrospectively, one thing can be sure: the reason why the wuxia rhetoric has produced seemingly magical powers in the writings of Pingiiang Buxiaosheng, Huanzhu Louzhu, Gu Mingdao, Gong Baiyu, and Wang Dulu is that they all share the context that they clash and create severe tension.

Different genres of literary work were competing for territory in the domain of literature. During this period, distinct literary forces fought to maintain or change the status quo of capital distribution, thereby maintaining or changing their positions. According to Pierre Bourdieu,

The relatively autonomous literary field gave way to an inverted economy, which was built on the essence of symbolic wealth with its unique logic. It is a reality with two sides, namely commodities and meanings, and its unique symbolic value and commodity value are relatively independent. Specialty leads to the emergence of cultural goods designed to the market, and the emergence of 'pure' works appropriated by symbolic use.

Quoted in DE BEAUVOIR, 1986: 23

In this process, producers that represent cultural production organizations choose side between two boundaries of symbolic wealth in alignment with market need, no matter whether it is explicit or implicit, objective or subjective. Zhu Guangqian believes that 'in modern China, a powerful literary publication has a broader and deeper influence than a university' (Zhu, 1996: 91), and the reason is self-evident. 
Before the 1920s, new literature and popular literature operated very differently, with the first type in the academy, and the other one in the publishing industry. Afterig21, Novel Monthly was drastically innovated by Mao Dun, and emerged with the Literary Research Association to incorporate new literature and popular literature into the network of newspapers and periodicals, bringing about multidimensional interactions that influenced the literary world in 1920 s and afterwards. Under the combined effects of pressure brought by the accumulation of symbolic capital by the new literature to break through the new literature, the commercial profits of the market economy, and the demand for leisure culture of citizens, leisure literature made full use of its realistic foundation. At that time, many major publishers launched magazines ${ }^{16}$ primarily targeting people living in urban areas. Wuxia novels with a wide range of readers and large sales volume became a literary genre that various popular newspapers and magazines competed for ever since the hot sale of PingjiangBuxiaosheng's Tales of the Extraordinary Xiake of Jianghu. All the above can be summed up in one phrase: the power of publications.

\subsection{Publishing Mechanism, Reading Ethics, and the 'Classification' of Jin Yong's Novels}

If we examine the 'canonization' of Jin Yong's wuxia novels in the twentieth century, it is difficult to skip past the transforming process of Jin Yong's novels from popular novels to 'classic' works, and how this affected the mechanisms of publishing.

With regard to the normative status of 'classics', standards may vary but conventions apply. No matter what standard we conform to, be it T. S. Eliot's 'mature' standard, Borges's 'reader' standard, Bloom's 'reread' standard, or Calvino's 'memory' standard, each essentially positions the 'classics' as containing two elements: universality and non-exhaustiveness. Looking at the 'distribution' and research status of Jin Yong's wuxia oeuvre, it may be regarded as a 'quasi-classic': not only has his collected works been translated into multiple languages, fifteen individual novels have been repeatedly adapted into film and television dramas, animations and various computer games. Moreover, research on Jin Yong's wuxia once attracted enormous scholarly attention, with

16 At that time, there were no less than twenty bookstores on Fuzhou Road in Shanghai, many of which launched their own publications. For example, the Commercial Press launched Novel Monthly, Zhonghua Book Company launched Chinese Novel World, Sao Ye Publishing House launched Art Magazine, and World Book Company launched Red Magazine. 
the unique research field of 'Jinology ${ }^{17}$ even being created. The English translator of The Deer and the Cauldron, John Minford, even compared The Deer and the Cauldron and Dream of the Red Chamber from the perspective of the translator. He believes that translating The Deer and the Cauldron is more difficult than Dream of the Red Chamber (indeed, more than any work he's translated) because, while Dream of the Red Chamber is comparatively universalistic, The Deer and the Cauldron is 'deep rooted in Chinese tradition' (Minford, 1997: 1-40). According to the standard of the second classic work referred to by Eliot ('the classic which is only such in relation to the other literature in its native language', Eliot, 1989: 186), if we applied Minford's comments hypothetically, then there is a distinct possibility that The Deer and the Cauldron could surpass Dream of the Red Chamber in the skillful operation of traditional Chinese language or thinking.

Returning to the publishing and reading situation of Jin Yong's wuxia novels, the wide popularity of Jin Yong in mainland China in the late 1970s was due to two 'publishing' channels of distribution. One was piracy. Jin Yong wrote in the preface to the Joint Publishing edition of his collected works:

The publishing process is very strange. Whether in Hong Kong, Taiwan, overseas, or on the Chinese mainland, all kinds of pirated copies are published first and then a legal version edited and authorized by me is published. On the Chinese mainland, before the publication of the Joint Publishing edition, only Tianjin Baihua Literature and Art Press published The Book and the Sword with my authorization.

JIN, 1994a: 2

17 In 1980 Taiwan's Vision Publishing House obtained the copyright of Jin Yong's novels and published the Jinxue Research Series, edited by Shen Deng'en. Each volume was written by a famous reviewer of Jin Yong's novels. Titles include: Jin Yong in the Eyes of Hundreds of Scholars (San Mao, Dong Qianli, Luo Longzhi, Lin Yanni, Weng Lingwen, Du Nanfa, etc.), Talking about the World in Jin Yong's Works and Continuing on the World in Jin Yong's Works (Yang Xing'an), Talking about 'The Smiling, Proud Wanderer'(WoonSweeOan), The Analysis of 'Fox Volant of the Snowy Mountain and Blade-Dance of the Two Lovers', Case Analysis of 'Demigods and Semi-Devils', and The Exploration of Love and 'The Return of the Condor Heroes' (all Chen Peiran), Reflections on Jin Yong (Shu Guozhi), Jin Yong's 'Wuxia' World (Su Qiaoji), Talking about Jin Yong (Pan Guosen), and Reading Jin Yong All Night (Xue Xingguo). Among them, Ni Kuang's Jin Yong's Novels in My Eyes was very popular, after that, four extra review books on Jin Yong were published in response to popular demand. 
The piracy of wuxia reached its peak in 1985. All of Jin's fifteen works were published and reached readers in on the Chinese mainland, and many books had multiple versions at the same time.

The second channel was serialization in local newspapers and magazines. Jin Yong's The Legend of the Condor Heroes was serialized by Guangzhou's Wulin magazine in the early 1980s. This was the first time a wuxia novel had been officially published on the Chinese mainland. However, this serialization stopped midway at the fourth instalment because pirated copies were running rampant and readers could read The Legend of the Condor Heroes in its entirety rather than wait for the next issue (Song, 1999: 35).

Although 'the defense of the classics can no longer be enforced by the power of the central system, nor can it be continued by the compulsory courses' (Kermode, 1985: 19), the formation of the classics cannot be independent of the 'system'. The above-mentioned popular methods of Jin Yong' wuxia make it a reading 'myth' among others, but it still remains a state of anonymity or namelessness in the mainstream culture. Therefore, when it comes to the definition of the quasi-classical status of Jin Yong's wuxia, researchers will generally begin the discussion based on the focus of Jin Yong's wuxia from the cultural centre system, such as academic recognition ${ }^{18}$ and the preference of a prominent publishing house. Among them, Joint Publishing launched thirtysix volumes of The Collection of Jin Yong's Works in 1994, one measure by which Jin Yong might be regarded as a master of literature:

For nearly ten years, many works have sold well on the Chinese mainland. After attracting large amounts of fans of wuxia novels, Jin Yong gained new momentum this year for his honorable recognition as a master of literature. In 1994 three consecutive events marked Jin Yong's entrance into the hall of fame and grand master status.... The third is the grand release of The Collection of Jin Yong's Works by Joint Publishing.

Southern People Weekly, 2006

As 'leisure' literature, wuxia novels were mainly serialized in newspapers and periodicals. In mainland China, several small and specialized publishing houses such as Zhongyuan Press and World Press published them as complete

18 In the 199os Peking University became the centre of Jin Yong wuxia research. In 1994 Wang Yichuan made an attempt to 'subvert the textbook'. When editor in chief of The Twentieth Century Chinese Literature Master Library Novel Volume, Wang listed Jin Yong after Lu Xun, Shen Congwen, and Ba Jin, and ahead of Lao She, Yu Dafu, and Zhang Ailing. Mao Dun was not on the list. When Xie Mian and Qian Liqun edited $A$ Century of Chinese Literary Classics, Jin Yong's The Legend of Condor Heroes was included as a 'Classic'. 
novels, as they did other wuxia novels. The publication of wuxia novels in Hong Kong and Taiwan were relatively concentrated. Specialized wuxia magazines such as Wu Yi, Wuxia World, Season of Wuxia, History and Wuxia, and so forth, were launched mainly in Hong Kong. In Taiwan, wuxia novels were published by Zhen Shan Mei, Chunqiu, Damei, Siwei, Haiguang, Mingxiang-Xinxing, Tsinghua-Xintai, and Nanqi publishing houses, among others. Thus the release of the Jin Yong collection by Joint Publishing has become a ground breaking event in the wuxia world.

Joint Publishing was the result of the final merger in 1948 between three leading publishers and bookstores: with Life Bookstore merged in 1936, Reading Press in 1935, and New Knowledge Bookstore in 1948. Joint Publishing operated in Beijing, Shanghai, and Hong Kong, publishing humanities and social sciences titles aimed at intellectuals with middle or higher educational backgrounds. It selected its titles based on its positioning on 'ideas, culture, and taste': 'In addition to the salience of cultural accumulation, another difference from others is the elegance and sophistication in the form of binding' (Wang, 1991: 10-13), Jin Yong's publications indeed represented quality and taste. Although the Joint Publishing edition of his Wuxia works was expensive, it nonetheless became a bestseller. It was published and reprinted several times, and more than 500,000 copies were sold in two years. It is undeniable that Joint Publishing's 'favor' symbolized a value shift for Jin Yong's wuxia: 'that is, it changed [his works] from pure novels with reading and consumption value to classic texts with collection value' (Song, 1999: 50).

In the long journey of the popularization, development, interpretation, acceptance, and 'canonization' of Jin Yong's wuxia novels, the earnest promotion and final publication of his collections by Joint Publishing, the 'elite' publishing house worldwide, was a transformative act for his great accomplishment.

\subsection{Who Made Crouching Tiger, Hidden Dragon? Analysis of 'Pre/Post Text' Adapted from Novels and Films}

Measured by commercial standards, the novels and films of Crouching Tiger, Hidden Dragon are extremely successful. In 1996 Crouching Tiger, Hidden Dragon, produced by Columbia Pictures Film Production Asia and directed by Ang Lee, made a global sensation after its release. It not only won multiple Oscar awards but generated one of the highest-grossing box office revenues in the United States, with a small production cost of $\$ 17$ million and total box office revenue of $\$ 213$ million. The US box office total was $\$ 128,078,872$ (6o\%) and outside the United States $\$ 85,446,864$ (40\%). Soon after, Qunzhong Publishing House bought the copyright from Wang Dulu's family and published 
Collections of Wang Dulu's Wuxia Romance Novels (in which Crouching Tiger, Hidden Dragon was first published). Many publishing houses in mainland China, Hong Kong, and Taiwan also released unauthorized and exquisitely bound volumes of Wang Dulu's Crouching Tiger, Hidden Dragon. As the fourth volume of the Crane Iron series of wuxia novels (after Crane Startles Kunlun, Precious Sword, Golden Hairpin, and Sword Force, Pearl Shine, and before Iron Knight, Silver Vase) in the late 1930s and early 1940s, its popularity can be compared with Jin Yong's wuxia. In 2005 two wuxia novels were selected in the 'Chinese Reader' of the People's Education Press for senior high school students; one is JinYong's Demi-Gods, Semi-Devils and the other is Crouching Tiger, Hidden Dragon.

In fact, the novel Crouching Tiger, Hidden Dragon originally had only a limited readership within a relatively small community. The novel was originally named The Legend of Crouching Tiger, Hidden Dragon and was serialized in Qingdao People's Daily from 16 March 1941 to 6 March 1942. It did not draw much attention at the time, since the war disrupted communication. After the victory against the Japanese, Shanghai Lili Bookstore began to print a large number of Wang Dulu's novels in 1948, ${ }^{19}$ but Crouching Tiger, Hidden Dragon was not on the list. After the founding of the People's Republic of China in 1949, wuxia novels were banned and Crouching Tiger, Hidden Dragon was buried in the dust. Although many researchers including Xu Sinian and Ye Hongsheng had been doing academic studies of it for some time, general readers had little knowledge of the book.

The turning point was the sweeping success of its film adaptation in 2000. However, the story of 'Yu Jiaolong' had been known to the readers for up to twenty years. As early as 1983, Legend of the Modern and Ancient Times magazine started to serialize a lengthy book called Yu Jiaolong in the third volume. Once published, it caused a sensation. Subscriptions to Legend of the Modern and Ancient Times had risen exponentially from 410,00o copies to 2.73 million copies. Authorship-wise, there is only a printed line 'Rewritten by Nie Yunlan' directly beneath the novel title; no further information of the original book or author are mentioned. Subsequently, the China Federation of Literary and Art Publishing House printed a single edition of Yu Jiaolong, and Nie Yunlan made both fame and fortune. During the period, Mrs Wang Dulu had several discussions on this matter with him via mail, and Nie Yunlan was very cooperative, so she did not make the matter public. In 1998 Sichuan Hongdu Company purchased the film and television adaptation rights of Yu Jiaolong

19 From October 1948 to April 1949, Shanghai Lili Bookstore published many novels by Wang Dulu, including Silver Dart with Embroidery Ribbons, Cold Sword, and many others. 
and Chunxueping from Nie Yunlan's children. In April 2001 the release of Yu Jiaolong edited by Nie Yunlan by Hubei People's Publishing House caused dissatisfaction with Wang Dulu's relatives, who believed that Hubei had seriously violated their legitimate rights and interests as the heir to the copyright bearer of Crouching Tiger, Hidden Dragon, and took Hubei and the book distribution centre of Xinhua Bookstore to the court.

During this period, Crouching Tiger, Hidden Dragon repeatedly gained public attention, as Nie Jialing, the son of Nie Yunlan, pointed out: 'Yu Jiaolong made the story of Crouching Tiger, Hidden Dragon more widespread and known to the public' (Yang cheng Evening News, 2000). (Since there is no URL webpage available, we made the following adaptations: Nie Yunlan's rewriting of Wang Dulu's novel Crouching Tiger, Hidden Dragon caused imitators to rewrite Wang Dulu's works. In reply to the questioning letter of Wang Dulu's wife Li Danquan regarding copyright, he apologized for this, "Although I asked myself about the purpose and motivation of the adaptation, the situation (time, situation) is different, but I am the 'initiator' after all!" (sohu, 2001) These can be regarded as products of the novel Crouching Tiger, Hidden Dragon. Taking the serialization of Crouching Tiger, Hidden Dragon in the 1930s as a purely literary phenomenon, the adaptation lawsuit in the 1980s and the film adaptation by Ang Lee in 2000 had complicated it into an amalgamation overlaid by multiple relations. Yet it would be wrong to think that these additions simply extend the text of Crouching Tiger, Hidden Dragon without simultaneously reorganizing this series of texts and readjusting the signification and value of individual texts.

By means of different textual forms, Crouching Tiger, Hidden Dragon is involved in different scopes of ideologies and cultural behaviours, and images of wandering heroes such as 'Yu Jiaolong' and 'Li Mubai' themselves wander around the texts and transform them into interconnected parts of the textual sequence. The current analysis of ideology and cultural behaviour in different scopes is obtained through the changes in significations of these images. For example, coordinating a series of overlapping issues centred on themes of class, nationality, gender, and so on, in Nie Yunlan's rewritten novel $Y u$ Jiaolong in the 1980s, the image of Liu Taibao (Xu, 2006: 67), the main character in the novel, could be elevated considering the adoption of class view point. Or, the award of Crouching Tiger, Hidden Dragon is linked to the games of media giants:

The success of Crouching Tiger, Hidden Dragon is actually the result of the painstaking management of American film companies. For American film companies, Crouching Tiger, Hidden Dragon is the 
touchstone for Hollywood to enter the Chinese market. Hollywood deliberately operates Crouching Tiger, Hidden Dragon this time, hoping to open up a huge Chinese market. With China's entering the wTo [World Trade Organization], China's film market will also open up to the outside world. This is an opportunity for them.

China News Network, 2001

Or we may point out that 'Crouching Tiger, Hidden Dragon fully reflects the Chinese filmmakers' enthusiasm for their own traditional culture in the process of learning western culture passionately' (Zeng, 2001: 115). After decades, the Crouching Tiger, Hidden Dragon text, through different contextual imprints, has been culturally activated in different ways and thus made it what it is today.

In general, the accompanying text can clarify the signification of wuxia signs. Previous research has only cited title, pen name, illustration, and book/ film review as supplementary elements to support the analysis of the 'main text'. But in fact, before the 'main text' appears in front of the interpreter, the meaning domain floating in these accompanying texts has pre-cued how to approach each such text.

\section{References}

$\mathrm{Bu}$, Feiyan (2005) 'Jianghu of the Beautiful Ladies' (红颜的江湖, Hong yan de jiang hu), Legend of Modern and Ancient Times: Wuxia Volume 3: 41.

Burke, Peter (2008) Eyewitnessing: The Uses of Images as Historical Evidence. Trans. Yang Yu. Beijing: Peking University Press.

Chen, Pingyuan (2010) Eternal Literati Knights Dream (千古文人侠客梦, Qian gu wen ren xia ke meng). Updated edition. Beijing: Peking University Press.

China News Network (2001) 'Crouching Tiger, Hidden Dragon is the Touchstone of American Filmmakers on the Chinese market', 27 March, 2001. http://ent.sina.com .cn/r/m/37731.html.

Cornelius, de Val (2003) Peirce. Trans. Hao Changchi. Beijing: Zhonghua Book Company. De Beauvoir, Simone (1986) The Second Sex. Trans. Sang Zhuying and Nan Shan. Changsha: Hunan Literature and Art Publishing House.

Eliot, T. S. (1989) 'What is a Classic Work?', in Elliott Poetics Collection, compiled by Wang Enzhong. Beijing: International Culture Publishing Company.

Foucault, Michel (1977) 'What is an Author?', in Donald F. Bouchard (ed.), Language, Counter-memory, Practice. Trans. Donald F. Bouchard and Sherry Simon. New York: Cornell University Press. 
Genette, Gerard (2000) Collection of Essays by Genette. Trans. Shi Zhongyi. Tianjin: Baihua Literature and Art Press.

Genette, Gerard (1977) Paratexts: Thresholds of Interpretation. Trans. Jane E. Lewin New York: Cambridge University Press.

Genette, Gerard (1988) 'The Proustian Paratexte', trans. Amy G. McIntosh, SubStance, $17(2): 63$.

Gould, Stephen Jay (1993) 'The Moral State of Tahiti -and of Darwin', in Stephen Jay Gould, Eight Little Piggies: Reflections in National History. New York and London: Norton.

Han, Yunbo (2004) 'On the New Chivalry Novels in Mainland China in 21st Century' (论21世纪大陆新武侠, Lun er shi yi shi ji da lu xin wu xia), Journal of Southwest University 4: 150-156.

Jin, Yong (1994a) The Collection of Jin Yong’s Works: Preface (金庸作品集“三联版’序,Jin yong zuo pinji 'san lian ban' $x u$ ). 36 vols. Beijing: Joint Publishing.

Jin, Yong (1994b) The Deer and the Cauldron (鹿鼎记, Lu ding ji). Volume 5 of The Collection of Jin Yong's Works. Beijing: Joint Publishing.

Jin, Yong (1994) The Heaven Sword and Dragon Sabre (倚天屠龙记, Yi tian tu long ji). Beijing: Joint Publishing.

Kermode, Frank (1985) Forms of Attention. Chicago, IL: University of Chicago Press.

Lin, Baochun (2011) Taiwan's Wuxia Novels and Wuxia Research (台湾的武侠小说与武 侠研究, Tai wan de wu xia xiao shuo yu wu xia yan jiu). https://bbs.gulongbbs.com/ archiver/?tid-2694.html, retrieved 12 April 2021.

Liu, Xie (2004) The Literary Mind and the Carving of Dragons (文心雕龙, Wen xin diao long). Changsha: Yuelu Bookstore.

Maclean, Marie (1991) 'Pretext and Paratexts: The Art of the Peripheral', New Literary History 2: 273-279.

Mao, Dun (1933) 'On the Feudal Civilian Literature' (封建的小市民文艺, Feng jian de xiao shi min wen yi), The Eastern Miscellany 3(3), 93-94.

Minford, John (1997) 'Kungfu in Translation, Translation as Kung Fu' (功夫的翻译, 翻 译的功夫, Gong fu de fan yi, fan yi de gong fu), in Liu Ching-chih (ed.), The Question of Reception: Martial Arts Fiction in English Translation. Hong Kong: Centre for Literature and Translation, Lingnan College [Lu Ding Ji with its English translation The Deer and the Cauldron was published by Oxford University Press in 1997 and 2000 respectively.].

Shuohuaren (1933) 'Speaking (Nine)' (说话, Shuo hua), Coral 21. 70-95.

Song, Weijie (1999) From the Act of Entertainment to the Utopian Impulse: Reinterpretation of Louis Cha's Novels (从娱乐行为到乌托邦冲动: 金庸小说再解读, Cong yu le xing wei dao wu tuo bang chong dong: jin yong xiao shuo zai jie du). Nanjing: Jiangsu People's Publishing House. 
Southern People Weekly (2006) '1994 Jin Yong Wuxia Master Enters the Hall of Fame', May 21, 2006: 34.

Wang, Yang (2007) 'The Western Female Quixote and Chinese Female Chivalry' (西方女吉诃德与中国女性武侠, Xi fang $n v$ ji he de yu zhong guo nv xing wu xia), Journal of Southwest University 5: 35-39.

Wang, Yaohua (1991) 'Analysis on the Characteristics of Book Publishing in Joint Publishing' (三联书店出书特色剖析, San lian shu dian chu shu te se pou xi), China Publishing Journal 5: 10-13.

Wang, Yichuan, ed. (1994) The Twentieth Century Chinese Literature: Fiction Volume (二十世纪中国文学大师文库 - 小说卷, ershi shi ji zhong guo wen xue da shi wen ku, xiao shuo juan). Haikou: Hainan Press.

$\mathrm{Xu}$, Sinian (2006) 'The Leap and Advancement of Vitality: Wang Dulu's Crouching Tiger, Hidden Dragon' (生命力的飞跃和突进 - 评王度庐的小说 “卧虎藏龙”, Sheng ming li de fei yue he tu jin - ping wang du lu de xiao shuo 'wo hu cang long'), Journal of Southwest University 3: 67.

Sohu.com (2001). The Scandal of Nie Yunlan's Rewriting, posted on February 22, 2001. Retrieved on April 12, 2021. https://yule.sohu.com/14/80/article144168o14.shtml.

Wang, Bi, Wei, Yuan (comment) (1992) The Recension of Tao De Jing (老子道德经注, Laozi dao de jing zhu). Shanghai: Shanghai Bookstore.

Yuan, Guoxing (2009) 'Invisibility and Concealment: The Influence of "Pen Name" on the Texture of Modern Chinese Literature in the Period of Occurrence' (隐身与 遮蔽: “笔名”对发生期中国现代文学质地的影响, Yin shen yu zhe bi: 'bi ming' dui fa sheng qizhong guo xian dai wen xue zhi di de ying xiang), Literary Review 3: 41.

Zeng, Ping (2001) 'Eastern Interpretation of Modern Emotions' (现代情感的东方 式演绎, Xian dai qing gan de dong fang shi yan yi), Journal of Southwest Minzu University 9: 115 .

Zhang, Dachun (2004) Xiaoshuo Bailei (小说稗类, Xiao shuo bai lei). Guilin: Guangxi Normal University Press.

Zhang, Gansheng (1991) Commentary on Popular Novels of the Republican China (民国通俗小说论稿, Min guo tong su xiao shuo lun gao). Chongqing: Chongqing Publishing House.

Zhang, Henshui (1981) 'Writing Career Memories' (写作生涯回忆, Xie zuo sheng ya huiyi), Journalism and Communication 1:192-193.

Zhang, Yuanshan (2001) 'The Story of a Pen Name' (笔名的故事, Bi ming de gu shi), Beijing Daily, 14 January, 2002:200.

Zhao, Yiheng (1994) The Distressed Narrator (苦恼的叙述者, Ku nao de xu shu zhe). Beijing: Beijing Shiyue Literature and Art Publishing House.

Zhao, Yiheng (2011) Principles and Deduction of Semiotics (符号学: 原理与推演, Fu hao xue yuan liyu tui yan). Nanjing: Nanjing University Press. 
Zheng, Yimei (1984) 'Common Faults in Martial Arts Novels' (武侠小说的通病, Wu xia xiao shuo de tong bing), in Rui Heshi and Fan Boqun (eds.), Literary Materials of the Mandarin Duck and Butterfly School, vol.1. Fuzhou: Fujian People's Publishing House.

Zhou, Zuoren (1981) Characters in Lu Xun's Novels (鲁迅小说里的人物, Lu Xun xao shuo li de ren wu). Beijing: People's Literature Publishing House.

Zhu, Guangqian (1996) Me and Literature and Others (我与文学及其他, Wo yu wen xue ji qi ta). Hefei: Anhui Education Publishing House. 